\title{
The determination of joint roughness coefficient using three-dimensional models for slope stability analysis
}

\author{
D.H. Kim School of Engineering, Griffith University, Australia \\ I. Gratchev School of Engineering, Griffith University, Australia \\ G.V. Poropat CSIRO Earth Science \& Resource Engineering, Australia
}

\begin{abstract}
Joint roughness coefficient $(J R C)$ is one of the important parameters to determine shear strength of joints. $J R C$ values are generally measured using profile gauges and estimated by comparing the surface profiles with typical roughness profiles. Therefore, the values can be subjective and vary depending on personal experience of an engineer. Digital photogrammetry methods provide 3D models based on high resolution digital images, and thus JRC values can be more objectively estimated from photogrammetry analysis using linear profile data.

This paper seeks to investigate the feasibility of using the photogrammetry method to obtain JRC values. Photogrammetry surveys were performed at several slope sites, and JRC values were estimated using $3 D$ images. To investigate the effect of resolution of digital images, the JRC values were first obtained using different distances between the slope and camera, and then compared with the roughness profiles which were manually measured by means of a Barton's comb. A computer analysis using the distinct element code UDEC was also performed to better understand the effect of JRC on the stability of slopes.
\end{abstract}

\section{Introduction}

Joint roughness coefficient (JRC) has been used in the analysis of the deformational behaviour of rock slopes. JRC values are traditionally estimated by comparing a section of discontinuities with typical roughness profiles (Barton and Choubey, 1977). However, the mapping process is quite labour-intensive, experience based and associated with risks during field works. In addition, manual measurements can be quite subjective (Grasselli and Egger, 2003; Milne et al., 2009) and yield personal errors.

In contrast, photogrammetry tends to provide more objective analysis minimising the possible risks involved in field works during slope investigation. This relatively recent technique has been successfully used to assess the stability of rock slopes providing vital information for both kinematic and numerical analyses (Brideau et al., 2012; Ferrero et al., 2011; Firpo et al., 2011). In addition, photogrammetry enables the determination of JRC using high resolution 3D models. Previous studies demonstrated that photogrammetric methods are able to characterise the geometry of joint roughness profiles (Haneberg, 2007; Poropat, 2008; Guo et al., 2011). However, the accuracy of JRC depends on the spatial density of digital images and the error related to the spatial data (Haneberg, 2007). Poropat (2009) noted that the process of data smoothing was essential for noise reduction so that reliable JRC values could be obtained.

The main objective of this paper is to examine the accuracy of JRCs obtained from 3D slope surface models and their effect on the stability of slopes. Photogrammetry investigations were performed for a natural slope on the Beaudesert Nerang road, Gold Coast (Queensland), and numerical analyses were carried out using a distinct element code to clarify the effect of JRC on the stability of slopes. 


\section{Traditional methods for JRC determination}

A standard way to determine JRC is the visual estimation using Barton's standard profiles (Barton and Choubey, 1977). JRC values, which vary from 0 to 20, are obtained through the comparison of the joint geometry with the standard profiles using a profile gauge (for example, a Barton's comb). Similarly, JRC values can also be estimated using relationship between length of profiles and the maximum amplitude of the profile. However, these visual estimations are rather subjective and experience is needed to obtain reliable values.

The tilt test is another approach to estimate JRC values. Barton and Choubey (1977) suggested a simple experiment to measure the tilt angle of rock samples with joints. Based on the obtained results, the JRC can be back-calculated using the following Equation 1.

$$
\mathrm{JRC}=\frac{\alpha-\emptyset_{\mathrm{r}}}{\log _{10}\left(\frac{\mathrm{JCS}}{\sigma_{\mathrm{no}}}\right)}
$$

Where:

$$
\begin{aligned}
& \alpha=\text { tilt angle. } \\
& \sigma_{n o}=\text { normal stress acting on the joint. } \\
& \mathrm{JCS}=\text { joint wall compressive strength. } \\
& \phi_{\mathrm{r}} \quad=\text { residual friction angle. }
\end{aligned}
$$

JCS values can be estimated using Schmidt hammer tests and residual friction angles can be defined by Equation 2.

$$
\emptyset_{\mathrm{r}}=\left(\emptyset_{\mathrm{b}}-20^{\circ}\right)+20(\mathrm{r} / \mathrm{R})
$$

Where:

$$
\begin{aligned}
& \phi_{\mathrm{b}} \quad=\text { basic friction angle. } \\
& \mathrm{r} \quad=\text { rebound number of the weathered joint wall (saturated). } \\
& \mathrm{R} \quad=\text { rebound number of dry unweathered surfaces of the rock. }
\end{aligned}
$$

\section{Application of photogrammetry to measure JRCs}

Recent studies on the roughness of rock surface using photogrammetry have shown a new way to determine the roughness characteristics of discontinuities. Haneberg (2007) and Poropat (2009) demonstrated that roughness profiles can be produced using photogrammetric point clouds following the approach developed by Maerz et al. (1990) and Tse and Cruden (1979). Maerz et al. (1990) proposed to estimate JRC using a regression equation that describes the relationship between the JRC and the roughness profile index, $R_{p}$, which is defined as the ratio of the true length of a fracture surface trace to its projected length in the fracture plane (Equation 3 ).

$$
J R C=411\left(R_{p}-1\right)
$$

Where:

$$
R_{p} \quad=\text { roughness profile index measured by photo analysis. }
$$

Tse and Cruden (1979) suggested a statistical approach to Barton and Choubey's standard joint surface profiles.

$$
\begin{gathered}
J R C=32.2+32.47 \log Z_{2} \\
J R C=37.28+16.58 \log S F
\end{gathered}
$$

Where: 
$Z_{2}=$ root mean square.

$\mathrm{SF}=$ mean square of the first derivative of the profile.

\section{$4 \quad$ Field surveys to determine JRCs}

Field surveys using photogrammetry were performed to investigate the feasibility of JRC estimation from 3D rock surface models as well as the effect of image resolution on the accuracy of 3D models. Also, an attempt was made to establish how precise photogrammetry can measure the joint roughness of rocks.

\subsection{Description of the study area}

The study area is located in Beaudesert Nerang road, Gold Coast (Queensland), Australia (Figure 1). Geological settings of this area include argillite and sandstone of the Neranleigh-Fernvale beds (Willmott, 2010, Gratchev et al., 2013). A slope with a length of around $200 \mathrm{~m}$ and a height of up to $10 \mathrm{~m}$ was selected for this study as this slope has experienced significant slope stability problems in the past few years. Field observations revealed that the rocks in this slope were heavily weathered, folded and steeply inclined (Figure 1(b)).
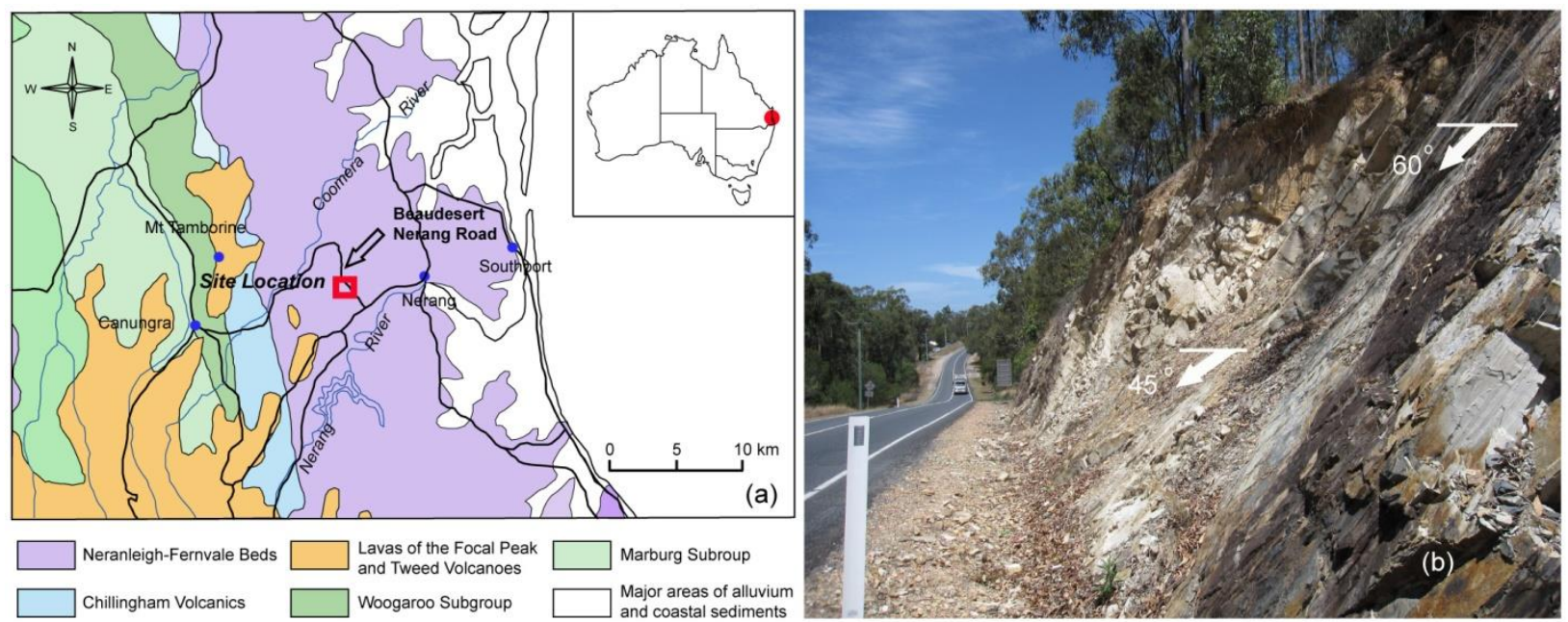

Figure 1 Location and geological condition of the study area; (a) geological map; (b) the failure area

\subsection{Photogrammetry survey}

A professional digital camera (Nikon D7000) with a focal length of $f=24 \mathrm{~mm}$ normal lens was employed to create 3D surface models. Calibration of the lens was performed to obtain high quality 3D images using the program iWitnessV2 (Photomatrix Pty Ltd). The camera position and its coordinates, as well as the coordinates of several control points were obtained using a GPS device. The computer code 'Sirovision' was utilised to analyse images and build 3D models.

\subsubsection{Georeferencing}

The slope was photographed from two points, with the distance between the camera positions being equal to $1 / 6$ the distance from the camera to the slope (CSIRO, 2005). Georeferencing was performed for the photo by determining the coordinates of the left camera position (using a GPS device), and measuring its bearing (azimuth) to the centre of slope (using a geological compass) (Sturzenegger, 2010).

After 3D models were built for the slope section, using the 'Sirovision' computer code, mapping of the major slope features, including measuring distances, were performed as shown in Table 1. Accuracy of the $3 \mathrm{D}$ model was obtained by comparing the measured distances between targets in three sections on the 
slope with their distances between the points on the 3D image (Figure 2). The 3D model showed good agreement with the distances of the guide points ranging the discrepancy between 0.4 and $1.0 \%$ of length. 
Table 1 The size of marked sections on the ${ }_{3} \mathrm{D}$ model compared to the manual measurements

\begin{tabular}{ccccccc}
\hline \multirow{2}{*}{ Sections } & \multicolumn{2}{c}{ Marked Distance $(\mathrm{m})$} & \multicolumn{2}{c}{ 3D Model $(\mathrm{cm})$} & \multicolumn{2}{c}{ Discrepancy (\%) } \\
& Horizontal & Vertical & Horizontal & Vertical & Horizontal & Vertical \\
\hline 1 & 0.5 & 0.5 & 0.503 & 0.497 & 0.6 & 0.6 \\
2 & 0.4 & 0.4 & 0.397 & 0.404 & 0.7 & 1.0 \\
3 & 0.5 & 0.5 & 0.502 & 0.504 & 0.4 & 0.8 \\
\hline
\end{tabular}
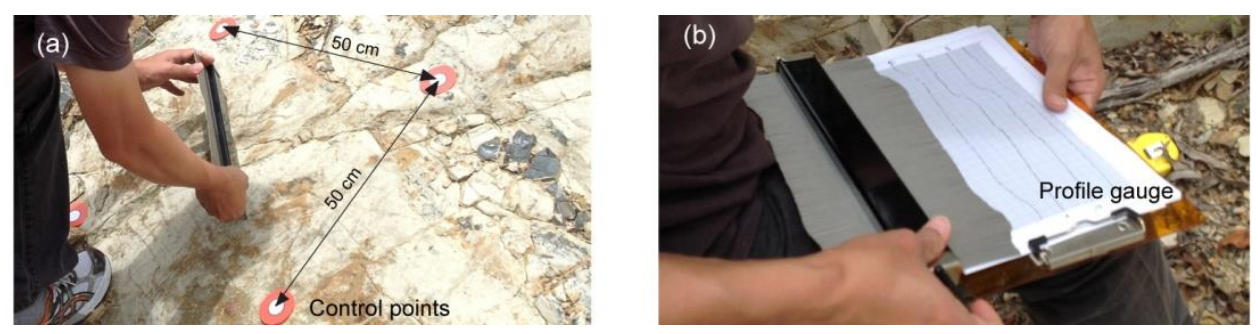

Figure 2 Manual measurement of joint roughness profiles; (a) control points; (b) profile gauge $(\mathrm{L}=25 \mathrm{~cm})$

In the three sections of the slope, roughness profiles were also measured by a Barton's comb for four different directions (dip direction and $45^{\circ}, 90^{\circ}, 135^{\circ}$ intervals). Directional roughness profiles extracted from the 3D model were visually compared to the measured profiles.

Table 2 summarises the JRC values obtained from both photogrammetry methods and manual measurements. It is evident from this table that the JRC obtained using the Barton's comb (manual measurements) has slightly higher values compared to those determined through the photogrammetry method. However, the difference between the JRC increases when the measuring planes differ from the plane of the dip (the steepest decent). Figure 3 indicates that the overall shape of the profiles extracted from the 3D model is consistent with the manual measurement. However, it was found that the surface roughness profiles obtained from the manual measurements were more detailed, providing more precise values of JRC. This difference can be attributed to the resolution of digital images as a higher resolution can produce larger number of points and thus more precise surface profiles (Haneberg, 2007). Guo et al. (2011) noted that the resolution of digital images needs to be increased to ensure the reliability of JRC values using photogrammetry. 

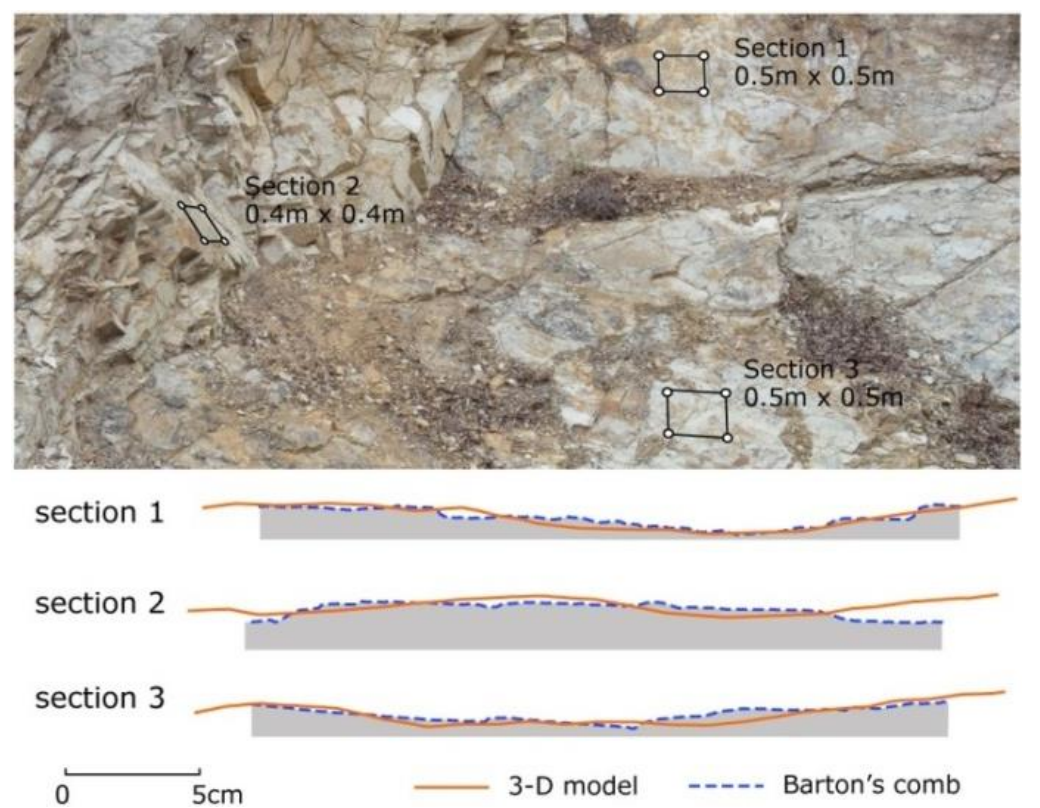

Figure 3 Comparison of roughness profiles between $3 \mathrm{D}$ model and manual measurement

Table 2 Comparison of JRC values between the photogrammetry method and the typical profile gauge method

\begin{tabular}{|c|c|c|c|c|c|c|c|c|c|}
\hline \multirow{3}{*}{ Direction } & \multicolumn{3}{|c|}{ Section 1} & \multicolumn{3}{|c|}{ Section 2} & \multicolumn{3}{|c|}{ Section 3} \\
\hline & \multicolumn{2}{|c|}{ 3D Model } & \multirow[b]{2}{*}{ Manual } & \multicolumn{2}{|c|}{ 3D Model } & \multirow[b]{2}{*}{ Manual } & \multicolumn{2}{|c|}{ 3D Model } & \multirow[b]{2}{*}{ Manual } \\
\hline & Maerz & $\begin{array}{l}\text { Tse and } \\
\text { Cruden }\end{array}$ & & Maerz & $\begin{array}{l}\text { Tse and } \\
\text { Cruden }\end{array}$ & & Maerz & $\begin{array}{l}\text { Tse and } \\
\text { Cruden }\end{array}$ & \\
\hline Steepest descent & 3.0 & 3.1 & 5.0 & 4.0 & 5.2 & 5.0 & 8.2 & 10.3 & 9.0 \\
\hline $45^{\circ}$ to steepest descent & 3.8 & 5.2 & 7.0 & 4.8 & 6.1 & 7.0 & 9.3 & 11.3 & 9.0 \\
\hline $90^{\circ}$ to steepest descent & 4.3 & 6.6 & 8.0 & 3.1 & 3.2 & 5.0 & 6.2 & 9.3 & 11.0 \\
\hline $135^{\circ}$ to steepest descent & 4.3 & 6.1 & 8.0 & 4.2 & 5.1 & 7.0 & 5.1 & 6.9 & 11.0 \\
\hline
\end{tabular}

\subsubsection{Effect of image resolution}

According to Haneberg (2007), the accuracy of JRC values greatly depends on the resolution of digital images. The pixel size of digital images is typically a function of the focal length, camera sensor sizes, and the distance between the camera and object (Sturzenegger and Stead, 2009). To clarify the effect of each parameter, different distances between the camera and slope $(D=2.0 \mathrm{~m}, 5.0 \mathrm{~m}, 10.0 \mathrm{~m})$ were used as shown in Figure 4 to produce images for 3D models. 

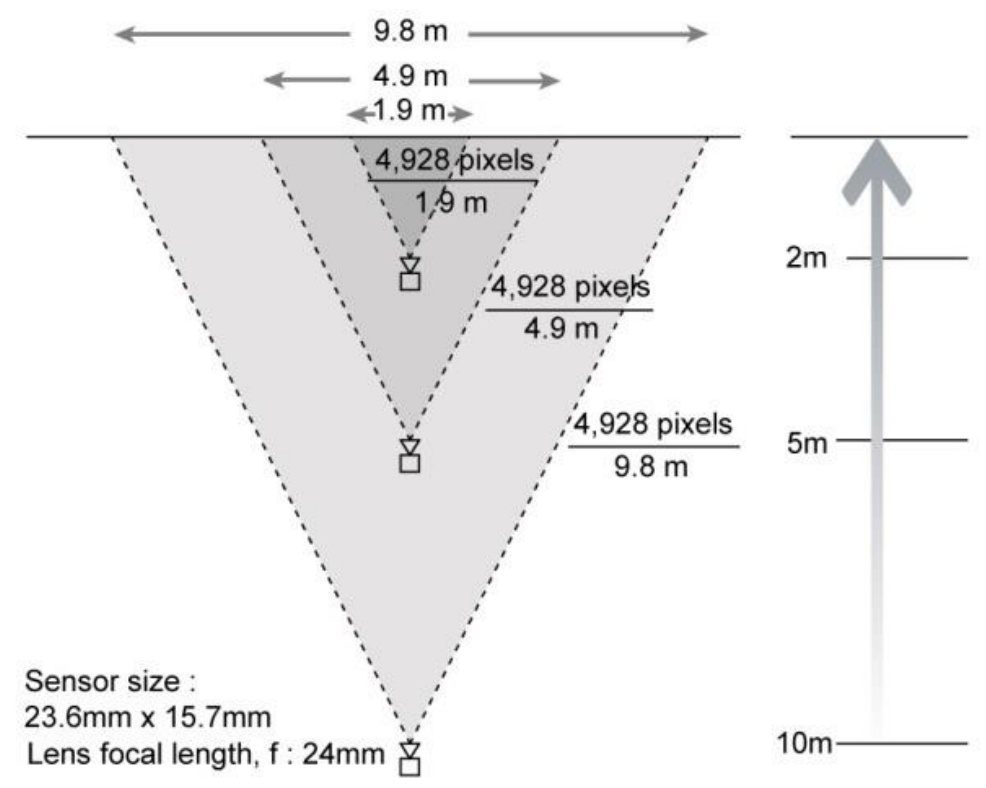

Figure 4 Schematic setup showing different distances from the camera and slope

Table 3 summarises pixel sizes of the images taken at different distances from the slope. Two control points were marked on the tested rock surface and the distance between the targets was $20 \mathrm{~cm}$. The area of the slope section was approximately $0.063 \mathrm{~m}^{2}$. The ground pixel size of each model was calculated using Equation 6 and the range of ground pixel sizes from 0.4 to $2.0 \mathrm{~mm}$.

$$
\mathrm{GPS}=\frac{\mathrm{d}}{\mathrm{f}} \times \operatorname{SPS}
$$

Where:

$$
\begin{aligned}
& \text { GPS }=\text { ground pixel size. } \\
& \mathrm{d} \quad=\text { distance from camera to rock surface. } \\
& \mathrm{f} \quad=\text { focal length of camera. } \\
& \text { SPS }=\text { sensor pixel size ( } 4.78 \mu \mathrm{m} \text { for Nikon D7000). }
\end{aligned}
$$

Figure 5 illustrates three models that were used to obtain surface roughness profiles. In case of $2 \mathrm{~m}$ distance, the pixel size is the high resolution producing more detailed images compared to the image taken from $10 \mathrm{~m}$ distance.

\section{Table 3 Distances from laser range finder measurement}

\begin{tabular}{ccccc}
\hline \multicolumn{2}{c}{ Camera Distance $(\mathrm{m})$} & \multicolumn{2}{c}{ Image Properties } \\
Between Camera and Targets & Between Cameras & Width $\times$ Height (Pixels) & Ground Pixel Size (mm) \\
\hline 2 & 0.4 & $376 \times 439(165,064)$ & 0.4 \\
5 & 1.0 & $112 \times 112(12,544)$ & 1.0 \\
10 & 2.0 & $64 \times 58(3,712)$ & 2.0 \\
\hline
\end{tabular}



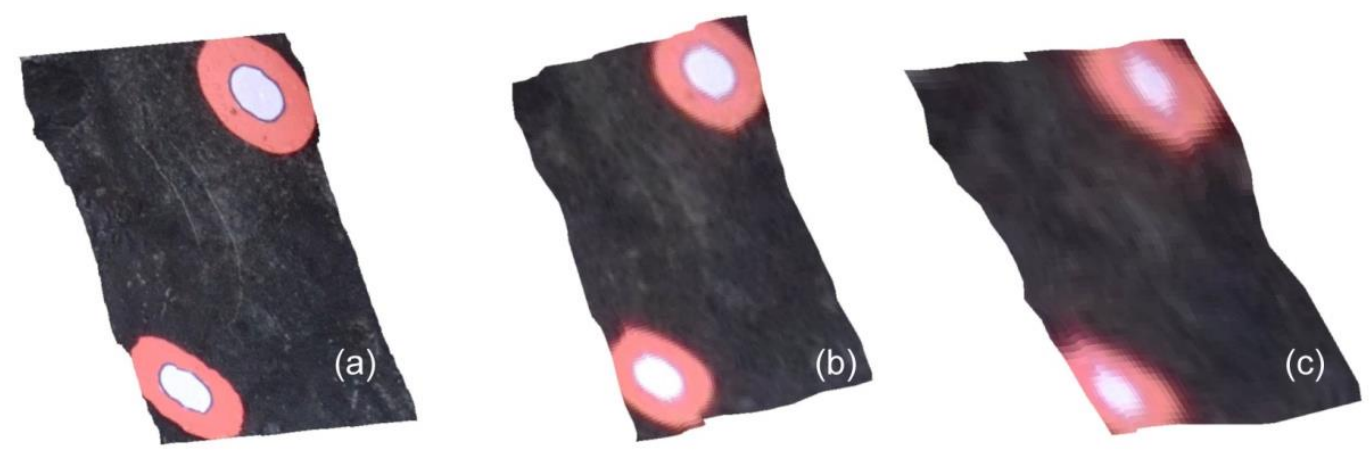

Figure 5 3D models due to decreasing of image density; (a) distance $=2.0 \mathrm{~m}$; (b) distance $=5.0 \mathrm{~m} ;(\mathrm{c})$ distance $=\mathbf{1 0 . 0 \mathrm { m }}$

The obtained roughness profiles were visually compared to the profile measured manually using a Barton's comb, as shown in Figure 6 . The comparison showed that the profiles generated from higher resolution images were more consistent with the measured profiles. Therefore, the discrepancy between the Barton's comb and the 3D model can be explained by lack of resolution of the images. Similarly, Haneberg (2007) investigated that the roughness profiles obtained from 3D images can be affected by the spatial density of xyz points, and the error associated with those points. Comparisons of JRC values at the three different camera distances are shown in Figure 7. The results indicated that the image at the closest distance produced the highest values of JRC in each direction. In addition, the high resolution 3D images taken from 2 and $5 \mathrm{~m}$ distances produced very large values of JRC (greater than 20). This can be attributed to the overestimation of JRC using both the Maerz and Tse-Cruden formulae (Poropat, 2008).

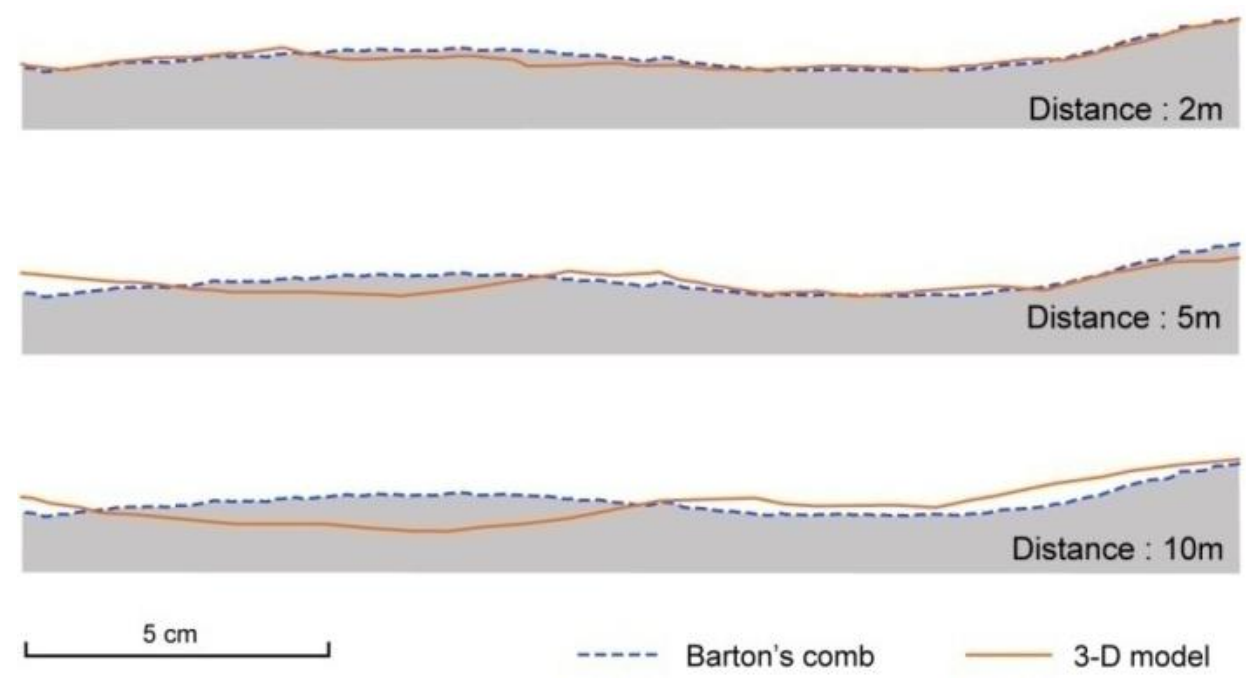

Figure 6 Comparisons of roughness profiles from $3 D$ models using different distances from the slope 

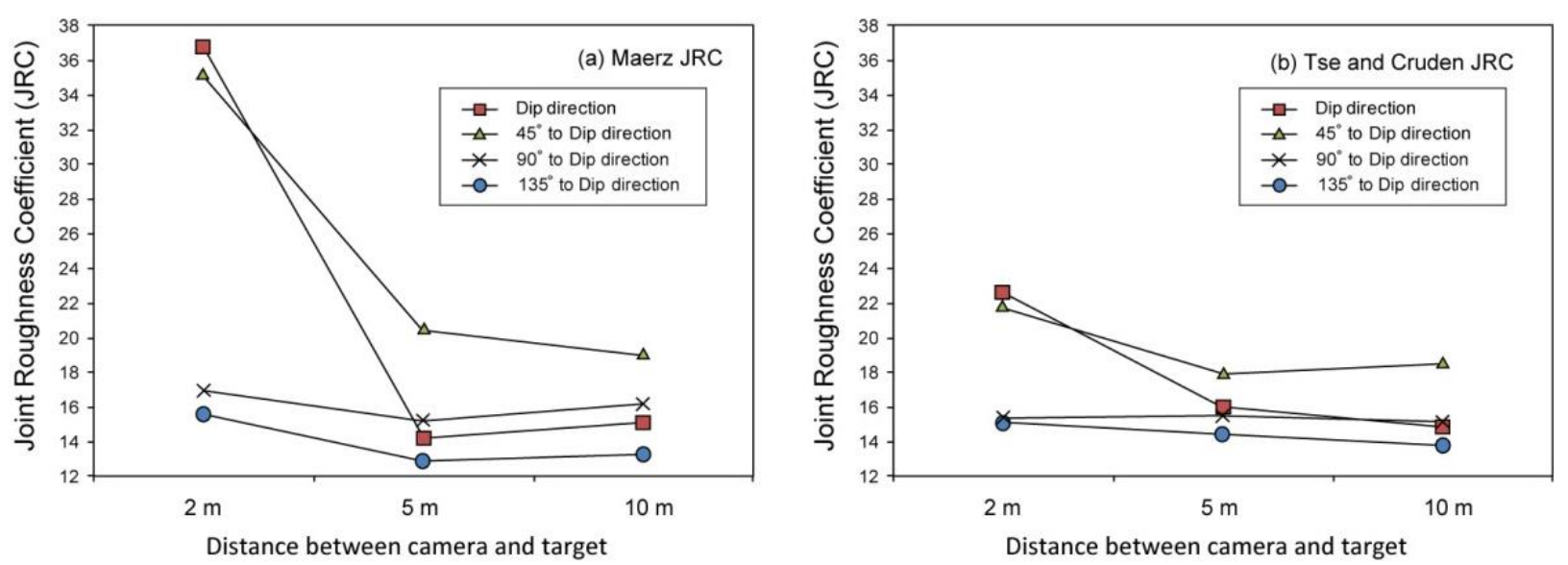

Figure 7 Comparison of JRC with different camera distance

\section{$5 \quad$ Slope stability analysis}

\subsection{Determination of JRC using 3D model}

$30 \mathrm{JRC}$ values were estimated on blocks of $30-50 \mathrm{~cm}$ at different locations as shown in Figure 8 to study the overall distribution of JRC in the slope. The roughness profiles were extracted for the steepest descent of each block. Figure 9 shows distribution of the JRC data, indicating that the mean value of JRC was 5.4 (using the Maerz function) and 6.5 (using the Tse and Cruden function). The result shows that the JRC obtained using the Tse and Cruden function has slightly higher values compared to those of the Maerz function.

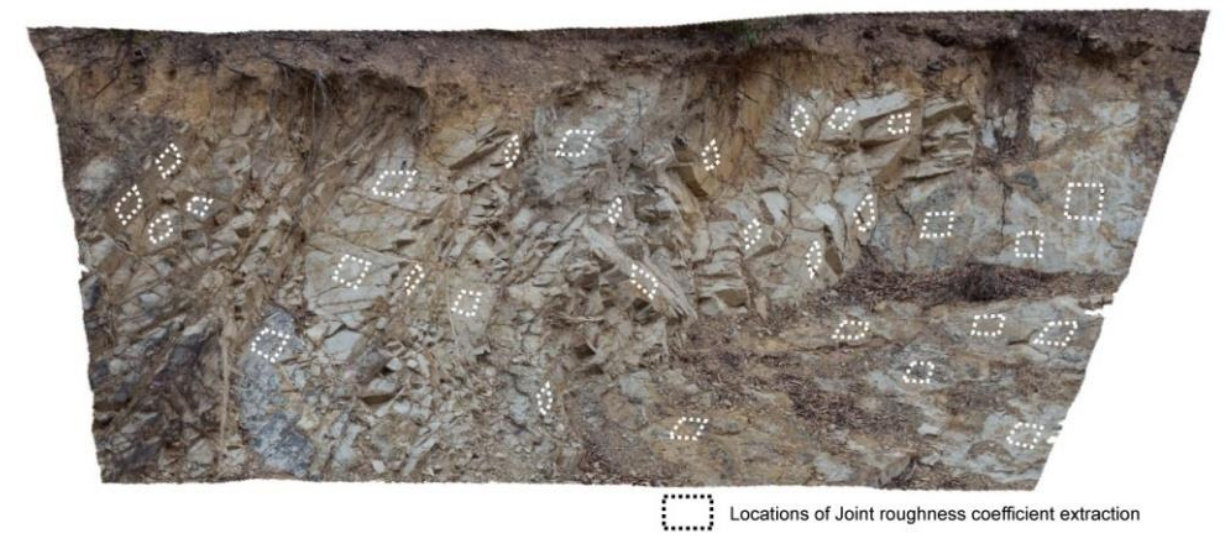

Figure 8 Roughness profiles extraction using the ${ }_{3} \mathrm{D}$ model

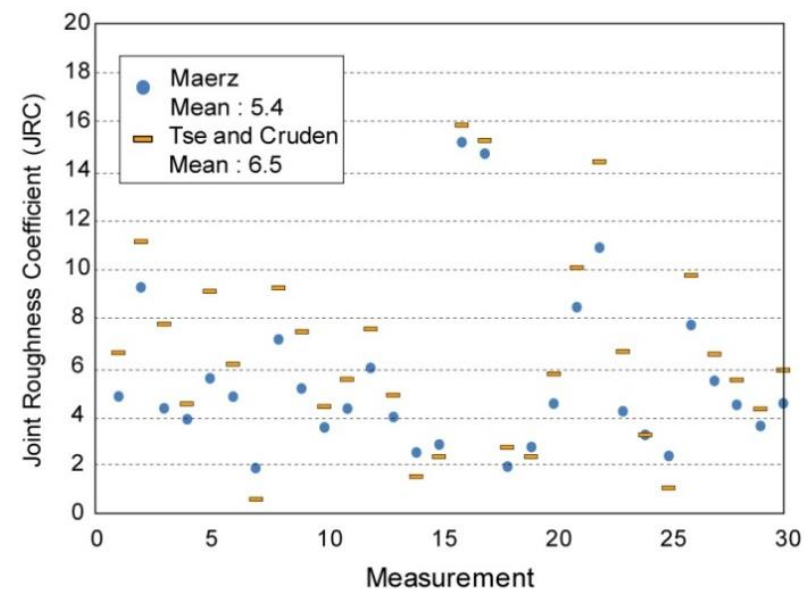

Figure 9 Distribution of JRC data 


\subsection{Numerical analysis}

To investigate the effect of JRC on the slope stability, the failure mechanism of the slope was examined by means of the Universal Distinct Element Code (UDEC). The joint spacing and orientations of main discontinuities were obtained from the 3D model. The analysis model was determined based on the near slope geometry. The JRC values obtained from the photogrammetry method and the manual measurements as well as the result from Schmidt hammer tests and point load tests were used to determine the joint strength properties. The Coulomb-slip model was utilised to describe the joint sets. Joint shear stiffness $\left(K_{s}\right)$ was calculated using Equation 7 (Barton and Choubey, 1977) and the joint normal stiffness was estimated by assuming the $K_{n} / K_{s}$ ratio to 3 . Table 4 summarises the properties of rock and rock joints adopted for the numerical analyses.

$$
\mathrm{K}_{\mathrm{s}}=\frac{100}{\mathrm{~L}_{\mathrm{x}}} \sigma_{\mathrm{n}} \tan \left[\mathrm{JRClog} \log _{10}\left(\frac{\mathrm{ICS}}{\sigma_{\mathrm{n}}}\right)+\emptyset_{\mathrm{r}}\right]
$$

Where:

$$
\begin{aligned}
& \mathrm{K}_{\mathrm{s}}=\text { joint shear stiffness }\left(\mathrm{MN} / \mathrm{m}^{2} / \mathrm{m}\right) . \\
& \mathrm{L}_{\mathrm{x}}=\text { joint length in metres. }
\end{aligned}
$$

Table 4 Joint parameters used for the UDEC simulation

\begin{tabular}{lcccc}
\hline \multicolumn{1}{c}{ Properties } & \multicolumn{3}{c}{ Analyses Cases } \\
& $\mathbf{1}$ & $\mathbf{2}$ & $\mathbf{3}$ \\
\hline Peak joint friction angle $\left({ }^{\circ}\right)$ & 35.0 & 38.3 & 41.9 \\
Joint roughness coefficient $(\mathrm{JRC})$ & 5.4 & 6.5 & 8.0 \\
Joint shear stiffness, $\mathrm{K}_{\mathrm{s}}(\mathrm{MPa} / \mathrm{m})$ & $3.35 \mathrm{E}+02$ & $4.25 \mathrm{E}+02$ & $5.68 \mathrm{E}+02$ \\
\hline
\end{tabular}

As a result, the slope was unstable (the Factor of Safety (FS) was less than 1). In all cases, the numerical models reached plastic failure with large amount of displacement. However, it was found that an increase in the JRC resulted in an increase of FS as described in Table 5. Figure 10 demonstrated that the thickness of failure zone expanded by decreasing of JRC from 8.0 to 5.4 .

Table 5 Comparative results of the UDEC simulation

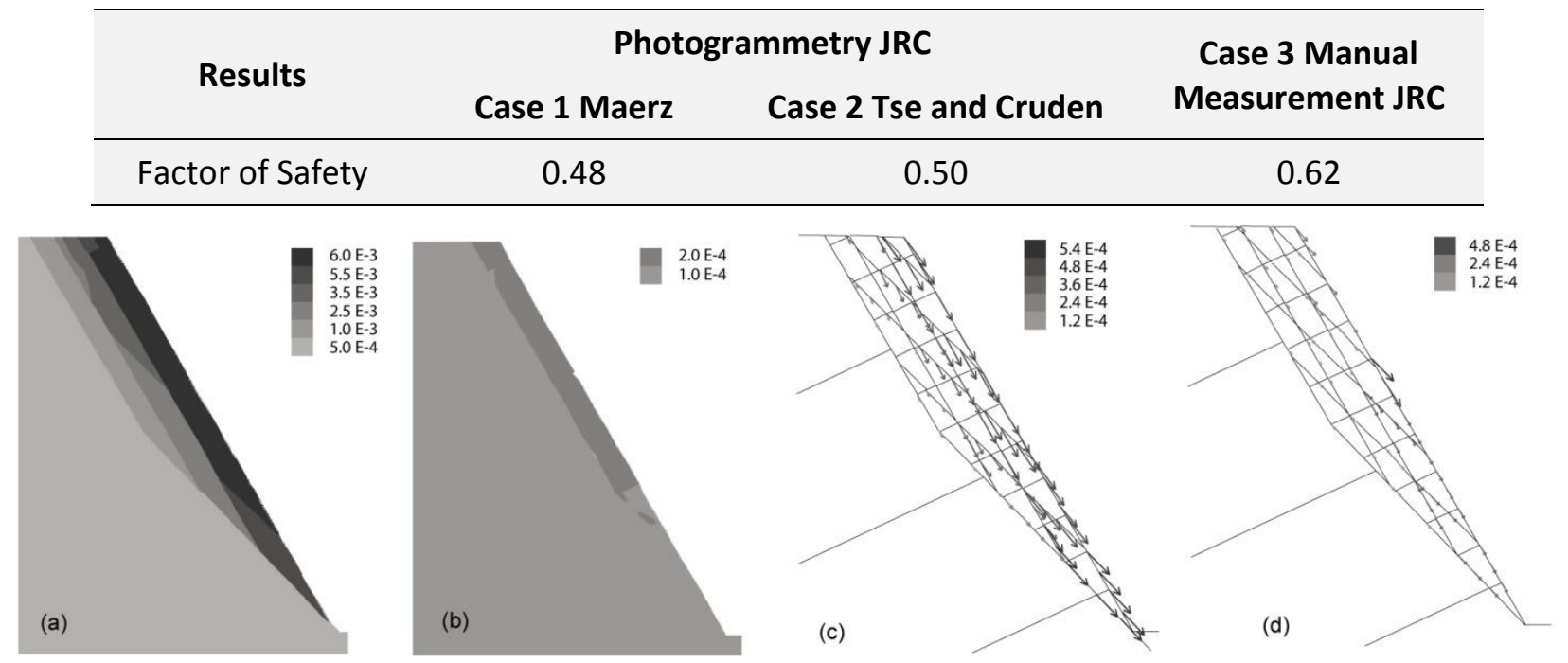

Figure 10 Displacement magnitude plot; (a) JRC = 5.4; (b) JRC = 8.0; displacement vector plot; (c) $J R C=5.4 ;(d) J R C=8.0$ 


\section{$6 \quad$ Conclusions}

This study demonstrated that photogrammetry can provide joint roughness profiles and JRC values which are similar to those obtained from field measurements using Barton's comb. However, the results also showed that there were discrepancies between the photogrammetry method and manual measurements. It was found that the differences can be mainly caused by the low resolution of the digital images. High resolution images at close distances from the slope had the tendency to overestimate JRC values. Using the $J R C$ values obtained from photogrammetry and manual measurements, joint mechanical properties were decided for numerical analysis. The numerical analyses indicated that the JRC had a significant influence on the Factor of Safety; that is, when the JRC increased the safety factor of the slope also increased.

\section{Acknowledgement}

The work was supported by the NRG grant from Griffith University, Australia. The authors thank Professor Doug Stead from Simon Fraser University, Canada for his valuable help.

\section{References}

Barton, N. and Choubey, V. (1977) The shear strength of rock joints in theory and practice, Rock Mechanics, Springer, Vol. 10, pp. 1-54.

Brideau, M-A., Sturzenegger, M., Stead, D., Jaboyedoff, M., Lawrence, M., Roberts, N., Ward, B., Millard, T. and Clague, J. (2012) Stability analysis of the 2007 Chehalis lake landslide based on long-range terrestrial photogrammetry and airborne LiDAR data, Landslides, Springer, Vol. 9, pp. 75-91.

CSIRO (2005) Field procedures for photogrammetric pit mapping, CSIRO Exploration and Mining.

Ferrero, A.M., Migliazza, M., Roncella, R. and Rabbi, E. (2011) Rock slopes risk assessment based on advanced geostructural survey techniques, Landslides, Springer, Vol. 8, pp. 221-231.

Firpo, G., Salvini, R., Franciani, M. and Ranjith, P.G. (2011) Use of digital terrestrial photogrammetry in rocky slope stability analysis by Distinct Elements Numerical Methods, International Journal of Rock Mechanics and Mining Sciences, Elsevier, Vol. 48(7), pp. 1045-1054.

Grasselli, G. and Egger, P. (2003) Constitutive law for the shear strength of rock joints based on three-dimensional surface parameters, International Journal of Rock Mechanics and Mining Sciences, Elsevier, Vol. 40(1), pp. 25-40.

Gratchev, I., Shokouhi, A., Kim, D.H., Stead, D. and Wolter, A. (2013) Assessment of rock slope stability using remote sensing technique in the Gold Coast area, Australia, in Proceedings 18th Southeast Asian Geotechnical \& Inaugural AGSSEA Conference, 29-31 May 2013, Singapore, Geotechnical Society of Singapore (GeoSS), Singapore, pp. 729-734.

Guo, H., Karekal, S., Poropat, G., Soole, P. and Lambert, C. (2011) Pit wall strength estimation with 3D imaging, CSIRO project paper, ACARP.

Haneberg, W.C. (2007) Directional roughness profiles from three-dimensional photogrammetric or laser scanner point clouds, in Proceedings Rock Mechanics: Meeting Society's Challenges and Demands, E. Eberhardt, D. Stead and T. Morrison (eds), 1st Canada-US Rock Mechanics Symposium, 27-31 May 2007, Vancouver, Canada, Taylor \& Francis, London, pp. 101-106.

Maerz, N.H., Franklin, J.A. and Bennett, C.P. (1990) Joint roughness measurement using shadow profilometry, International Journal of Rock Mechanics and Mining Sciences, Elsevier, Vol. 27, pp. 329-343.

Milne, D., Hawkes, C. and Hamilton, C. (2009) A new tool for the field characterization of joint surface, in Proceedings 3rd CANUS Rock Mechanics Symposium, M. Diederichs and G. Grasselli (eds), 9-15 May 2009, Toronto, Canada, paper 4169.

Poropat, G.V. (2008) Remote characterisation of surface roughness of rock discontinuities, in Proceedings First Southern Hemisphere International Rock Mechanics Symposium (SHIRMS), Y. Potvin, J. Carter, A. Dyskin and R. Jeffery (eds), Vol. 2 Fundamental and Petroleum, 16-19 September 2008, Perth, Australia, Australian Centre for Geomechanics, Perth, pp. 447-458.

Poropat, G.V. (2009) Measurement of Surface Roughness of Rock Discontinuities, in Proceedings 3rd CANUS Rock Mechanics Symposium, M. Diederichs and G. Grasselli (eds), 9-15 May 2009, Toronto, Canada, paper 3976.

Sturzenegger, M. (2010) Multi-scale characterization of rock mass discontinuities and rock slope geometry using terrestrial remote sensing techniques, PhD Thesis, Simon Fraser University.

Sturzenegger, M. and Stead, D. (2009) Close-range terrestrial digital photogrammetry and terrestrial laser scanning for discontinuity characterization on rock cuts, Engineering Geology, Elsevier, Vol. 106, pp. 163-182.

Tse, R. and Cruden, D.M. (1979) Estimating joint roughness coefficients, International Journal of Rock Mechanics and Mining Sciences, Elsevier, Vol. 16, pp. 303-307.

Willmott, W. (2010) Rocks and landscape of the Gold Coast hinterland, Geological Society of Australia, Queensland Division. 
The determination of joint roughness coefficient using three-dimensional models for D.H. Kim et al. slope stability analysis 